\title{
Drastic increase of myosin light chain MLC-2 in senescent skeletal muscle indicates fast-to-slow fibre transition in sarcopenia of old age
}

\author{
Joan Gannon ${ }^{\mathrm{a}}$, Philip Doran ${ }^{\mathrm{b}}$, Anne Kirwan ${ }^{\mathrm{a}}$, Kay Ohlendieck ${ }^{\mathrm{a}, *}$ \\ ${ }^{a}$ Department of Biology, National University of Ireland, Maynooth, Co. Kildare, Ireland \\ ${ }^{\mathrm{b}}$ Department of Biological Chemistry, University of California, Los Angeles, CA, USA
}

Received 6 March 2009; received in revised form 25 June 2009; accepted 27 June 2009

\begin{abstract}
The age-dependent decline in skeletal muscle mass and function is believed to be due to a multi-factorial pathology and represents a major factor that blocks healthy aging by increasing physical disability, frailty and loss of independence in the elderly. This study has focused on the comparative proteomic analysis of contractile elements and revealed that the most striking age-related changes seem to occur in the protein family representing myosin light chains (MLCs). Comparative screening of total muscle extracts suggests a fast-to-slow transition in the aged MLC population. The mass spectrometric analysis of the myofibril-enriched fraction identified the MLC2 isoform of the slow-type MLC as the contractile protein with the most drastically changed expression during aging. Immunoblotting confirmed an increased abundance of slow MLC2, concomitant with a switch in fast versus slow myosin heavy chains. Staining of two-dimensional gels of crude extracts with the phospho-specific fluorescent dye ProQ-Diamond identified the increased MLC2 spot as a muscle protein with a drastically enhanced phosphorylation level in aged fibres. Comparative immunofluorescence microscopy, using antibodies to fast and slow myosin isoforms, confirmed a fast-to-slow transformation process during muscle aging. Interestingly, the dramatic increase in slow MLC2 expression was restricted to individual senescent fibres. These findings agree with the idea that aged skeletal muscles undergo a shift to more aerobic-oxidative metabolism in a slower-twitching fibre population and suggest the slow MLC2 isoform as a potential biomarker for fibre type shifting in sarcopenia of old age.

(C) 2009 Elsevier GmbH. All rights reserved.
\end{abstract}

Keywords: Aging; Myofibril; Myosin light chain; Myosin heavy chain; Sarcopenia

\section{Introduction}

The age-dependent weakening of contractile strength and loss in skeletal muscle mass, termed sarcopenia of old age (Morley et al., 2001), is related to a

\footnotetext{
*Corresponding author. Tel.: + 35317083842 ; fax: +35317083845 .

E-mail address: kay.ohlendieck@nuim.ie (K. Ohlendieck).
}

multiplicity of biochemical and cell biological changes (Vandervoort, 2002; Doherty, 2003; Rolland et al., 2008). Muscle wasting in the elderly is probably not simply due to one specific sarcopenia-inducing gene or limitations in rates of cellular turn-around, but more likely triggered by a multi-factorial aetiology (Thompson, 2009). Striking histological alterations in aged skeletal muscles include an extensive variability in fibre diameter, an increased number of centrally located nuclei, 
grouped atrophying fibres and a higher frequency of longitudinal splitting (Edstrom et al., 2007). Previous studies into muscle aging have clearly documented the complexity of pathological changes (Faulkner et al., 2007), including a severe decline in contractile efficiency (Prochniewicz et al., 2007), mitochondrial abnormalities (Chabi et al., 2008), metabolic alterations (Vandervoort and Symons, 2001), a progressive decline in energy intake (Thomas, 2007), a drastically decreased regenerative capacity (Lorenzon et al., 2004), disturbed ion homeostasis (O'Connell et al., 2008a), uncoupling between neuronal excitation and muscle contraction (Delbono et al., 1995), decreased capillarisation (Degens, 1998), oxidative stress (Squier and Bigelow, 2000), a partially diminished cellular stress response (Kayani et al., 2008), impaired protein synthesis of myofibrillar components (Balagopal et al., 1997), increased apoptosis (Marzetti and Leeuwenburgh, 2006), denervationassociated atrophy (Carlson, 2004) and an altered equilibrium of growth factors and hormones important for the maintenance of proper muscle function (Lee et al., 2007).

Over the last few years, numerous proteomic investigations have catalogued the skeletal muscle protein complement from various species and have also determined disease-related changes in protein expression, including aging-induced alterations in muscle fibres as reviewed by Doran et al. (2009). The proteomic profiling of crude soluble extracts has revealed a severely perturbed protein expression pattern in aged muscles involving enzymes of various metabolic pathways, regulatory components of ion homeostasis and elements of the cellular stress response (Piec et al., 2005; Gelfi et al., 2006; O'Connell et al., 2007; Doran et al., 2008; Lombardi et al., 2009; Capitanio et al., 2009). Altered post-translational modifications affecting tyrosine nitration, tyrosine/threonine phosphorylation and N-glycosylation were recently documented to occur to a large extent during biological aging of skeletal muscle fibres (Kanski et al., 2005; Gannon et al., 2008; O'Connell et al., 2008b). The proteomic finding that the ratelimiting glycolytic enzyme pyruvate kinase is greatly reduced in aged muscle, while the expression of key mitochondrial proteins is increased in sarcopenia, strongly suggests a shift towards a more aerobicoxidative metabolism in senescent muscle fibres. Although aged fibres exhibit an overall blunted stress response (Kayani et al., 2008), the proteomic screening of aged muscles demonstrated a drastic increase in certain muscle-specific chaperones (Doran et al., 2007a). The age-related stress response via small heat shock proteins may relate to the metabolic and structural changes associated with sarcopenia. Therefore, the upregulation of stress proteins may represent an autoprotective mechanism of damaged muscle fibres (Koh, 2002) and can be considered a natural response to the disintegration of the actomyosin machinery. Since the recent analysis of crude total fibre extracts suggests a considerable impact of aging on the contractile apparatus (Piec et al., 2005; Gelfi et al., 2006; Doran et al., 2008; Capitanio et al., 2009), we have investigated here the agedependent effect on protein expression in the myofibrilenriched fraction using comparative subproteomics.

The question of whether it is feasible to determine subtle changes in the density and/or isoform expression pattern of contractile proteins by proteomic techniques has been recently addressed by the mass spectrometric analysis of chronic low-frequency stimulated fast muscles (Donoghue et al., 2005, 2007). This is not a trivial point, since the biomolecules forming the thick and thin filaments of the basic contractile units in skeletal muscles exist in numerous fibre type-specific isoforms (Pette and Staron, 1990). Skeletal muscle myosin forms a hexameric structure consisting of 2 myosin heavy chains (MHCs) and various MLCs (Clark et al., 2002; Bozzo et al., 2005). Molecular coupling between the myosin head structure and actin filaments, in the presence of ATP, causes the sliding of thin filaments past thick filaments resulting in sarcomeric shortening (Gordon et al., 2000; Fitts, 2008). The $\mathrm{Ca}^{2+}$ dependent regulation of actomyosin interactions occurs via the troponin complex and tropomyosin strands (Swartz et al., 2006; Kreutziger et al., 2007). During electrostimulation-induced muscle transformation, the various light and heavy chains of myosin undergo a stepwise replacement from fast to slow isoforms, which has also been shown to occur in the case of regulatory elements such as the individual subunits of troponin (Pette and Staron, 2001). Proteomic investigations have clearly confirmed these changes in the isoform expression pattern of the contractile apparatus (Donoghue et al., 2007), demonstrating that two-dimensional gel electrophoresis in combination with mass spectrometric analysis is capable of detecting delicate alterations in the skeletal muscle proteome.

In analogy, our comparative proteomic analysis of young adult versus senescent myofibrils presented here has identified MLC-2 (Kumar et al., 1986) as being drastically increased during aging. This finding agrees with the idea of an aging-induced shift to a slower twitching fibre population, predominantly expressing slow isoforms of key contractile proteins. Therefore, this study complements the previous proteomic analyses of aged fibres (Doran et al., 2008) and expands the list of potential candidates for establishing a comprehensive biomarker signature of sarcopenia. The detailed knowledge of changed expression levels of individual muscle markers may be useful in the future biochemical evaluation of novel therapeutic approaches and improved exercise programmes, as well as the testing of superior dietary supplements to prevent muscle wasting in the elderly. 


\section{Materials and methods}

\section{Materials}

For the gel electrophoretic analysis of muscle proteins, isoelectric focusing $\mathrm{pH}$ gradient (IPG) DryStrips, ampholytes, acetonitrile and a silver staining kit were purchased from Amersham Bioscience/GE Healthcare (Little Chalfont, Bucks, UK). Ultrapure Protogel acrylamide stock solutions were obtained from National Diagnostics (Atlanta, GA, USA). Protease inhibitors were obtained from Roche Diagnostics (Mannheim, Germany). For immunoblotting experiments, nitrocellulose sheets were purchased from Millipore (Bedford, MA, USA), chemiluminescence substrate from Pierce and Warriner (Chester, UK) and X-ray film from Fuji Photo Film Co. Ltd. (Tokyo, Japan). The fluorescent phosphoprotein gel stain Pro-Q Diamond was from Molecular Probes (Eugene, OR, USA). For immuno fluorescence microscopy, diamidino-phenylindole (DAPI) was from Sigma Chemical Company (Dorset, UK) and Superfrost Plus positively-charged microscope slides were obtained from Menzel Glaeser (Braunschweig, Germany). Primary antibodies were from Abnova, Taipei City, Taiwan (mAb MYL2 to the slow MLC2 isoform), Upstate Biotechnology, Lake Placid, NY (mAb SKB1 to Akt/PKB kinase) and Sigma ( $\mathrm{mAb}$ NOQ7.54D to the slow $\mathrm{MHC}_{\mathrm{s}}$ isoform; $\mathrm{mAb}$ MY-32 to the fast $\mathrm{MHC}_{\mathrm{f}}$ isoforms IIA, IIB, IID; pAb L9393 to laminin). Secondary fluorescent or peroxidase-conjugated antibodies were purchased from Molecular Probes and Chemicon International (Temecula, CA), respectively. For proteomic peptide analysis, sequencing-grade modified trypsin was from Promega (Madison, WI, USA). All other chemicals were of analytical grade and obtained from Sigma Chemical Company.

\section{Animal model of skeletal muscle aging}

The aged gastrocnemius muscle from Wistar rats was used as an established tissue model of sarcopenia. Freshly dissected muscle specimens from 3-month- and 26-month-old rats, representing young adult versus aged contractile tissue, were obtained from the Animal Facility of the Department of Physiology, Trinity College Dublin. For one set of comparative proteomic analyses, a combination of 6 biological repeats and 2 technical repeats was carried out for each age group. Statistical evaluations were carried out with an unpaired Student's $t$-test. All rats used in this study were fed ad libidum and kept at a standard light-dark cycle with unrestricted movement in standard animal house cages (Nolan et al., 2005). The activity level of the younger rat population was enhanced as compared to the older cohort. Both human and rat muscles share common age-related changes (Edstrom et al., 2007), making 26-month-old Wistar rat muscle a suitable model system to study age-dependent adaptations in sarcopenia (Doran et al., 2007b). Rat muscle aging is associated with fibre degeneration, altered fibre type size, changed fibre proportions, the incomplete recruitment of distinct fibre groupings and overall contractile weakness (Larsson and Edstrom, 1986; Alnaqeeb and Goldspink, 1987; Edstrom and Larsson, 1987; Larsson et al., 1991; Cutlip et al., 2007).

\section{Preparation of myofibrillar fraction for electrophoretic analysis}

The majority of electrophoretic and immunoblotting experiments were performed with the myofibrillar fraction from young adult versus aged rat gastrocnemius muscle. Myofibrils were isolated from tissue homogenates by an established method (Zhukarev et al., 1997). Muscle strips were homogenised in 10 volumes of icecold buffer (10 mM TES, pH 7.1, $3 \mathrm{mM} \mathrm{MgCl}_{2}$ and $10 \mathrm{mM}$ EGTA) using an Ultra-Turrax T25 (IKA-Labortechnik, Staufen, Germany) for 3 times $30 \mathrm{~s}$ at medium speed. The homogenate was centrifuged at $1500 \mathrm{~g}$ for $5 \mathrm{~min}$ at $4{ }^{\circ} \mathrm{C}$ and the myofibril-enriched pellet then washed four times with the above described homogenisation buffer (Bassaglia et al., 2005). Subsequently $200 \mathrm{mg}$ of the myofibrillar fraction was resuspended in $1 \mathrm{ml}$ of ice-cold lysis buffer, containing $7 \mathrm{M}$ urea, $2 \mathrm{M}$ thio-urea, $65 \mathrm{mM}$ Chaps, $10 \mathrm{mM}$ Trisma base, $1 \%$ (v/v) ampholytes, $\mathrm{pH} 3-10$, and $100 \mathrm{mM}$ DTT. To avoid excessive proteolysis of isolated myofibrils, the suspension was supplemented with a protease inhibitor cocktail $(0.15 \mu \mathrm{M}$ aprotinin, $0.3 \mu \mathrm{M}$ E-64, $0.2 \mathrm{mM}$ prefabloc, $0.5 \mathrm{mM}$ soybean trypsin inhibitor, $1 \mu \mathrm{M}$ leupetin, $1.4 \mu \mathrm{M}$ pepstatin, $1 \mathrm{mM}$ EDTA). The myofibril suspension was carefully mixed by vortexing and then placed on a bench top shaker for $2.5 \mathrm{~h}$ at room temperature to precipitate the total protein fraction. Following centrifugation at $20,000 \mathrm{~g}$ for $20 \mathrm{~min}$, the resulting protein pellet was washed in $5 \mathrm{ml}$ of ice-cold concentrated acetone and thoroughly broken up by vortexing and sonication. The centrifugation and washing step was repeated twice with $80 \%$ (v/v) acetone. The final protein precipitate was resuspended in $1 \mathrm{ml}$ of buffer ( $7 \mathrm{M}$ urea, $2 \mathrm{M}$ thio-urea, $65 \mathrm{mM}$ Chaps, $1 \%$ (v/v) ampholytes, $\mathrm{pH} 3-10,100 \mathrm{mM}$ DTT) by gentle pipetting and vortexing. The subcellular fractionation process yielded approximately $60 \mathrm{mg}$ of total myofibril protein using $1 \mathrm{~g}$ of muscle as starting material. The protein lysate was incubated for $1 \mathrm{~h}$ at room temperature with gentle vortexing every $10 \mathrm{~min}$ for $5 \mathrm{~s}$, and then subjected to isoelectric focusing. 


\section{Preparation of crude muscle extracts for electrophoretic analysis}

For comparative purposes and in order to verify proteomic findings from the analysis of myofibrilenriched fractions, altered expression levels of contractile proteins were determined in the total muscle protein complement. Crude tissue extracts were prepared from young adult versus aged gastrocnemius muscle by an optimized method (Doran et al., 2007a). Freshly dissected muscle strips of $100 \mu \mathrm{g}$ were quick-frozen and pulverized in liquid nitrogen. The muscle tissue powder was resuspended in $1 \mathrm{ml}$ of ice-cold buffer ( $7 \mathrm{M}$ urea, $2 \mathrm{M}$ thio-urea, $65 \mathrm{mM}$ Chaps, $10 \mathrm{mM}$ Trisma base, $1 \%$ (v/v) ampholytes, $\mathrm{pH} 3-10,100 \mathrm{mM}$ DTT). The suspension was then carefully mixed by vortexing and placed on a bench top shaker for $2.5 \mathrm{~h}$ at room temperature to precipitate the total protein fraction. Treatment with acetone, washing, centrifugation and resuspension in the final buffer were carried out as described above for the myofibril-enriched preparation.

\section{Gel electrophoretic analysis}

One-dimensional gel electrophoresis of the myofibrilenriched fraction was carried out with a MiniProtean III gel system (BioRad Laboratories, HemelHempstead, Herts., UK) by a standard method using $12 \%$ separation gels (O'Connell et al., 2008a). Twodimensional gel electrophoresis of the total muscle proteome and the myofibril proteome for densitometric and mass spectrometric analyses was performed as previously described in detail by our laboratory (Doran et al., 2004). Isoelectric focusing was achieved with an Amersham IPGphor system using the following running conditions: $30 \mathrm{~V}$ for $2 \mathrm{~h}, 500 \mathrm{~V}$ for $2.5 \mathrm{~h}, 1000 \mathrm{~V}$ for $1 \mathrm{~h}$, $2000 \mathrm{~V}$ for $1 \mathrm{~h}, 4000 \mathrm{~V}$ for $1 \mathrm{~h}, 6000 \mathrm{~V}$ for $1 \mathrm{~h}, 8000 \mathrm{~V}$ for $3 \mathrm{~h}, 500 \mathrm{~V}$ for $1.5 \mathrm{~h}$ and finally $8000 \mathrm{~V}$ for $2.5 \mathrm{~h}$. Following equilibration and washing in running buffer (Doran et al., 2007a), the separation of muscle protein complements in the second dimension was carried out with $12 \%$ resolving gels in a Bio-Rad Protean Xi-ll cell. Following electrophoresis for $2 \mathrm{~h}$ at $30 \mathrm{~V}$ and a $80-\mathrm{V}$ step until the bromophenol blue dye front had just run off the gel, two-dimensional gels were stained with various dyes. Colloidal Coomassie staining of protein gels was carried out according to Neuhoff et al. (1988). For a more sensitive detection of muscle proteins, silver staining was carried out by the method of Chevallet et al. (2006). For image analysis, 6 gels representing young adult muscle and 6 gels representing aged muscle were scanned using Image Scanner II from GE Healthcare. Images were analysed with Progenesis SameSpots software. In order to evaluate the phosphorylation status of the slow MLC-2 protein, two-dimensional gels of crude muscle extracts were labelled with the fluorescent Pro-Q Diamond phosphoprotein gel stain (Stasyk et al., 2005), as optimized by our laboratory (Gannon et al., 2008). Following fixation and washing, gels were incubated with the undiluted fluorescent ProQ-Diamond dye for $4 \mathrm{~h}$ in the dark. Fluorescently labelled muscle proteins were visualized using the above described Typhoon scanner, and images were scanned using a 532-nm laser with a PMT value for all scanned images of 600 . Gel images were cropped using the Image-Quant TL software programme. Gels were also stained for total protein with the dye ruthenium II bathophenanthroline disulfonate chelate (RuBPs; Rabilloud et al., 2001). Comparative analysis of the MLC-2 spot was performed with the Image Master Platinum 5 analysis software package.

\section{Mass spectrometric identification of muscle proteins}

The mass spectrometric analysis of peptides was carried out in the Proteomics Suite of the National University of Ireland, Maynooth with a Model 6340 Ion Trap LC/MS apparatus from Agilent Technologies (Santa Clara, CA) and in the Molecular Instrumentation Center of the University of California at Los Angeles with a LTQ-Orbitrap hybrid mass spectrometer from ThermoFisher Scientific (Fremont, CA). Excision, washing, destaining and treatment with trypsin was performed by an optimized method for the mass spectrometric identification of muscle proteins (Doran et al., 2004, 2007a). Peptides generated by tryptic digestion were recovered by removing supernatants from digested gel plugs. Further recovery was achieved by adding $30 \%$ acetonitrile $/ 0.2 \%$ trifluoric acid to the gel plugs for $10 \mathrm{~min}$ at $37^{\circ} \mathrm{C}$ with gentle agitation. Resulting supernatants were added to the initial peptide recovery following trypsin digestion. Exhaustive peptide recovery was achieved through the addition of $60 \%$ acetonitrile $/ 0.2 \%$ trifluoric acid to each plug for $10 \mathrm{~min}$ at $37^{\circ} \mathrm{C}$ with gentle agitation. Supernatants were added to the peptide pool. The sample volume was reduced until dry through vacuum centrifugation. Samples were resuspended in $30 \mu \mathrm{l}$ ultrapure $\mathrm{ddH}_{2} \mathrm{O}$ and $0.1 \%$ formic acid for identification by ion trap LC-MS analysis. Separation of peptides was performed with a nanoflow Agilent 1200 series system, equipped with a Zorbax $300 \mathrm{SB} \mathrm{C} 185 \mu \mathrm{m}, 4 \mathrm{~mm} 40 \mathrm{nl}$ pre-column and a Zorbax 300SB C18 $5 \mu \mathrm{m}, 43 \mathrm{~mm} \times 75 \mu \mathrm{m}$ analytical reversedphase column using the HPLC-Chip technology (Staples et al., 2009). Mobile phases utilized were A: $0.1 \%$ formic acid, B: $50 \%$ acetonitrile and $0.1 \%$ formic acid. Samples $(15 \mu \mathrm{l})$ were loaded into the enrichment at a capillary flow rate set to $4 \mu \mathrm{l} / \mathrm{min}$ with a mix of $\mathrm{A}$ and $\mathrm{B}$ at a ratio 19:1. Tryptic peptides were eluted with a linear gradient of $10-90 \%$ solvent $\mathrm{B}$ over $40 \mathrm{~min}$ with a constant nano 
pump flow of $0.6 \mathrm{ml} / \mathrm{min}$. A 10 -min post time of solvent A was used to remove sample carryover. The capillary voltage was set to $1700 \mathrm{~V}$. The flow and the temperature of the drying gas was $41 / \mathrm{min}$ and $300^{\circ} \mathrm{C}$, respectively. For protein identification, database searches were carried out with two different software packages, i.e. Spectrum Mill Work Bench (Agilent Technologies) and Mascot MS/MS Ion search (Matric Science, London, UK). All searches used 'Rattus norvegicus' as taxonomic category and the following parameters: (i) two missed cleavages by trypsin, (ii) mass tolerance of precursor ions $\pm 2.5 \mathrm{Da}$ and product ions $\pm 0.7 \mathrm{Da}$, (iii) carboxymethylated cysteins fixed modification, and (iv) oxidation of methionine as variable modification. In addition, the percentage coverage was set at over $10 \%$, with at least 1 matched distinct peptide. Importantly, all pI-values and molecular masses of identified proteins were compared to the relative position of their corresponding two-dimensional spots on analytical slabs gel. For the analysis with the LTQ-Orbitrap hybrid mass spectrometer, the apparatus was equipped with an Eksigent nano-LC pump. Reconstituted peptides were separated on a pre-packed PicoFrit Biobasic C18 analytical column from New Objective (Woburn, MA). Mobile phase A was $0.1 \%$ formic acid and $2 \%$ acetonitrile in water. Mobile phase B consisted of $0.1 \%$ formic acid in acetonitrile. The resolving gradient was set as follows: initially, the separation was performed using $5-40 \%$ of buffer B over $40 \mathrm{~min}$, and then increased to $40-100 \%$ of buffer B over 20 min and maintained at $100 \%$ of buffer B for $10 \mathrm{~min}$. The mass spectrometer was operated in a data-dependent mode with one full MS on the Orbitrap ( $\mathrm{R}=60,000)$, followed by $5 \mathrm{MS} / \mathrm{MS}$ scans on the LTQ. Monoisotopic precursor selection was applied to eliminate redundant detection of ions within the same isotopic envelope. The mass accuracy of the Orbitrap was calibrated externally on a weekly basis. All MS/MS spectra were searched against the IPI Rat database (version 3.57) using the SEQUEST algorithm integrated within Proteome Discoverer (Thermo Scientific, San Jose, CA) and the Mascot algorithm (www.matrixscience.com). For identification of rat muscle proteins, the search parameters for LTQ-Orbitrap were set as follows: partial trypsin digestion with 2 missed cleavages; differential modifications on cysteine carbamidomethylation $(+57.02 \mathrm{Da})$ and methionine oxidation $(+15.99 \mathrm{Da})$; precursor ion tolerance of $\pm 10 \mathrm{ppm}$ and fragment tolerance of $\pm 0.5 \mathrm{Da}$.

\section{Immunoblot analysis}

Immunoblotting was carried out as previously described by our laboratory (Doran et al., 2007a). For the efficient electrophoretic transfer of proteins to Immobilon NC-pure nitrocellulose membranes, a Bio-Rad
Mini-Protean II transfer system was employed. Following transfer for $1 \mathrm{~h}$ at $100 \mathrm{~V}$ and $4{ }^{\circ} \mathrm{C}$, the efficiency of transfer was evaluated by Ponceau-S-Red staining of membranes, followed by de-staining in phosphatebuffered saline (PBS; $50 \mathrm{mM}$ sodium phosphate, $0.9 \%$ (w/v) NaCl, $\mathrm{pH}$ 7.4). Membranes were blocked for $1 \mathrm{~h}$ in $5 \%(\mathrm{w} / \mathrm{v})$ fat-free milk powder in PBS and then incubated for $3 \mathrm{~h}$ at room temperature with appropriately diluted primary antibody. Nitrocellulose blots were subsequently washed twice for $10 \mathrm{~min}$ in blocking solution and incubated with an appropriate dilution of the corresponding peroxidase-conjugated secondary antibody for $1 \mathrm{~h}$ at room temperature. Membranes were washed twice for $10 \mathrm{~min}$ in blocking solution and twice rinsed for 10 min with PBS. Immuno-decorated protein bands were visualised using the SuperSignal-type enhanced chemiluminescence system from Pierce and Warriner (Chester, Cheshire, UK). Densitometric scanning of immunoblots was performed on a Molecular Dynamics 300S computing densitometer (Sunnyvale, CA, USA) with Imagequant V3.0 software.

\section{Microscopic analysis of isolated myofibrils and whole-muscle cryosections}

For the microscopic evaluation of the quality of the subcellular fractionation procedure, a drop of the myofibril-enriched suspension was positioned on a glass slide and investigated by bright-field microscopy and immunofluorescence staining with an antibody to actin (Zhukarev et al., 1997). The immunofluorescence survey of myosin isoforms in transverse tissue sections from gastrocnemius muscle was carried out according to Doran et al. (2008). Cryosections of $10 \mu \mathrm{m}$ thickness were prepared with the help of a Shandon Cryotome (Life Sciences International, Cheshire, UK) at $-20^{\circ} \mathrm{C}$. Young adult and aged gastrocnemius sections were mounted on positively-charged microscopy slides, fixed in ice-cold acetone for $5 \mathrm{~min}$, left briefly to dry at room temperature, and then washed by submergence in icecold PBS. For immuno-labelling, cryosections were first blocked in $0.2 \%(\mathrm{w} / \mathrm{v})$ bovine serum albumin, $0.2 \%$ $(\mathrm{v} / \mathrm{v})$ Triton $\mathrm{X}-100$, and $2.5 \%(\mathrm{v} / \mathrm{v})$ goat serum in PBS for $30 \mathrm{~min}$, and then incubated with appropriately diluted primary antibodies for $4 \mathrm{~h}$. Sections were washed twice for $30 \mathrm{~min}$ in $0.2 \%(\mathrm{w} / \mathrm{v})$ BSA and $0.2 \%(\mathrm{v} / \mathrm{v})$ Triton X-100 in PBS, incubated for $1 \mathrm{~h}$ with Alexa Fluor-conjugated secondary antibodies and washed for $30 \mathrm{~min}$ prior to microscopy. Labelling of nuclei was achieved by incubation of tissue sections with $1 \mu \mathrm{g} / \mathrm{ml}$ DAPI for $30 \mathrm{~min}$. Image acquisition was carried out with an Olympus FluoView FV1000 confocal laser scanning microscope (Olympus Life and Material Science Europe, Hamburg, Germany) using the Olympus FluoView Version 1.3c software package. 

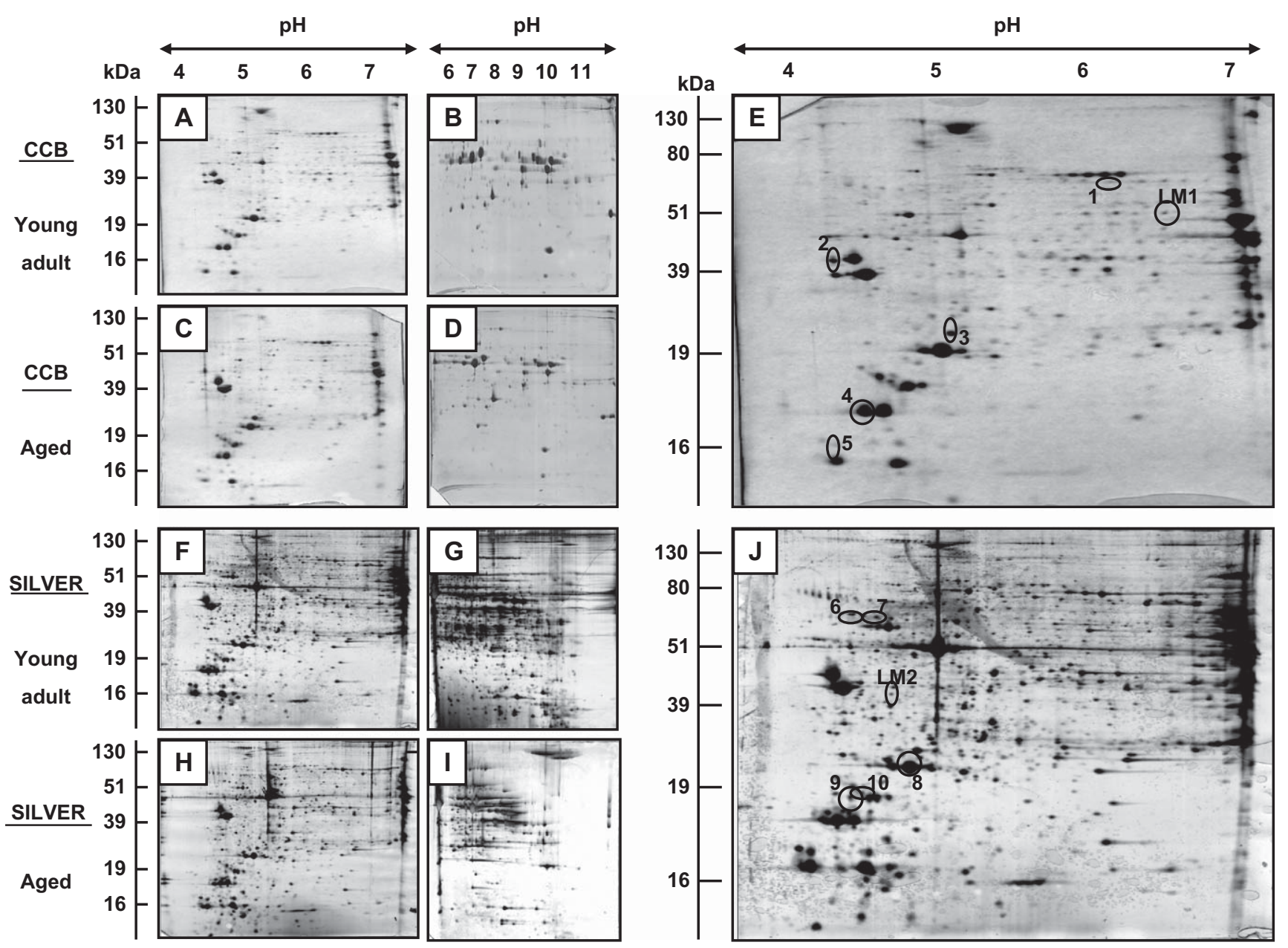

Fig. 1. Two-dimensional gel electrophoretic analysis of young adult versus aged muscle. Crude tissue extracts were isolated from young adult $(\mathrm{A}, \mathrm{B}, \mathrm{F}, \mathrm{G})$ and aged $(\mathrm{C}, \mathrm{D}, \mathrm{H}, \mathrm{I})$ rat gastrocnemius muscle, separated by two-dimensional gel electrophoresis and stained with colloidal Coomassie Blue (A-E) or silver (F-J). Proteins with an age-related change in abundance are marked 1 to 10 (E, J) and spot numbers correspond to their mass spectrometric identification as listed in Table 1.

Table 1. Proteomic profiling of aged contractile proteins using crude tissue extracts.

\begin{tabular}{|c|c|c|c|c|c|c|c|c|}
\hline $\begin{array}{l}\text { Spot } \\
\text { no. }\end{array}$ & Protein & $\begin{array}{l}\text { Peptides } \\
\text { matched }\end{array}$ & $\begin{array}{l}\text { Sequence } \\
\text { coverage } \\
(\%)\end{array}$ & $\begin{array}{l}\text { Molecular } \\
\text { mass } \\
(\mathrm{kDa})\end{array}$ & $\begin{array}{l}\text { Isoleletric } \\
\text { point }(\mathrm{pI})\end{array}$ & $\begin{array}{l}\text { Mascot } \\
\text { score }\end{array}$ & $\begin{array}{l}\text { Accession } \\
\text { number }\end{array}$ & $\begin{array}{l}\text { Fold } \\
\text { change }\end{array}$ \\
\hline 1 & $\begin{array}{l}\text { Myosin-binding protein } \\
\mathrm{H}\end{array}$ & 10 & 24 & 63.35 & 6.02 & 779 & gi $|149058581|$ & +1.57 \\
\hline 2 & Tropomyosin 1 & 3 & 17 & 22.68 & 4.86 & 153 & gi $|149045748|$ & +1.82 \\
\hline 3 & Myosin light chain 3 & 20 & 86 & 22.16 & 5.03 & 709 & gi $|6981240|$ & +3.29 \\
\hline 4 & Myosin light chain, fast & 3 & 28 & 18.97 & 4.82 & 367 & gi $6981238 \mid$ & -1.64 \\
\hline 5 & Myosin light chain, fast & 4 & 22 & 21.87 & 4.85 & 156 & gi $|149016008|$ & -1.74 \\
\hline 6 & Actin, alpha & 11 & 20 & 42.37 & 5.23 & 145 & IPI00189813 & -1.70 \\
\hline 7 & Actin, alpha & 3 & 14 & 42.37 & 5.23 & 86 & IPI00189813 & -1.60 \\
\hline 8 & $\begin{array}{l}\text { Myosin light chain, fast } \\
1 \mathrm{~F}\end{array}$ & 9 & 52 & 20.68 & 4.99 & 399 & gi $|117676401|$ & -1.50 \\
\hline 9 & Myosin light chain 2 & 5 & 27 & 19.07 & 4.82 & 106 & IPI00231787 & +1.50 \\
\hline 10 & Troponin $\mathrm{T}$, fast & 9 & 14 & 30.73 & 6.19 & 81 & IPI00554262 & -1.70 \\
\hline LM1 & Enolase & 6 & 25 & 53.90 & 5.81 & 604 & gi $|109468300|$ & -1.91 \\
\hline LM2 & ATP synthase & 11 & 29 & 56.35 & 5.18 & 278 & gi|54792127| & +1.80 \\
\hline
\end{tabular}



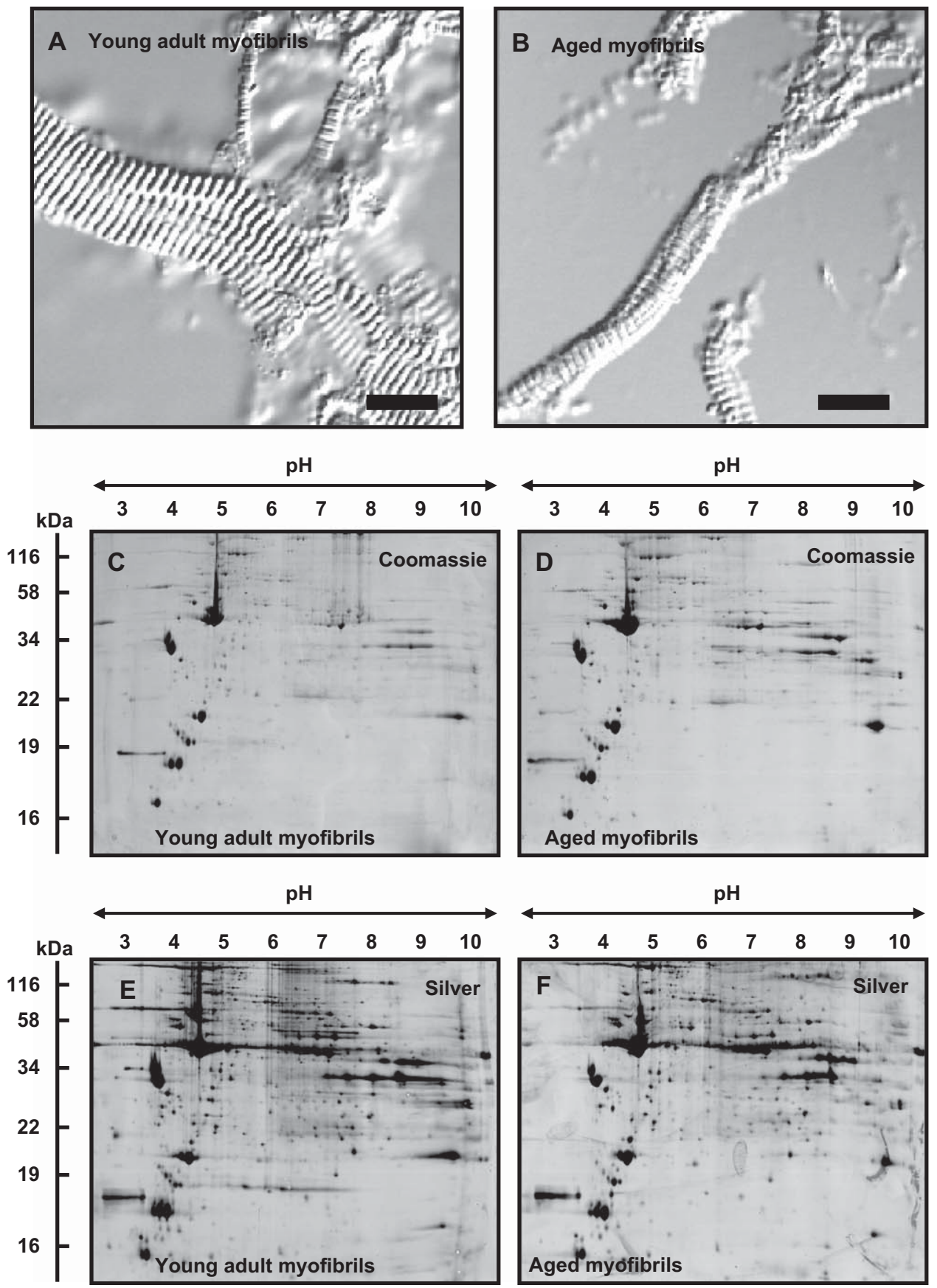

Fig. 2. Two-dimensional gel electrophoretic analysis of young adult $(\mathrm{C}, \mathrm{E})$ versus aged (D, F) myofibrils. The myofibril-enriched fraction was isolated from rat gastrocnemius homogenates by differential centrifugation and evaluated by bright-field microscopy (A, B) prior to comparative gel electrophoretic analysis. Bars: $10 \mu \mathrm{m}$. Gels were stained with colloidal Coomassie Blue (C, D) or silver $(\mathrm{E}, \mathrm{F})$.

\section{Results}

In contrast to previously published proteomic studies on aged rat muscle, as reviewed by Doran et al. (2009), this report describes a refined analysis of age-dependent skeletal muscle degeneration in two respects. Firstly, this investigation has employed narrower first dimension $\mathrm{pH}$-gradients for a more detailed electrophoretic evalua- tion of expression changes in contractile proteins in the total senescent skeletal muscle proteome (Fig. 1; Table 1). Secondly, the focus of a subproteomic screening exercise was on the contractile apparatus and its molecular fate during aging, using a myofibril-enriched fraction (Figs. 2-5; Table 2). Subsequently, the phosphorylation status and subcellular localisation of one of the most drastically altered contractile proteins, MLC-2, 
A

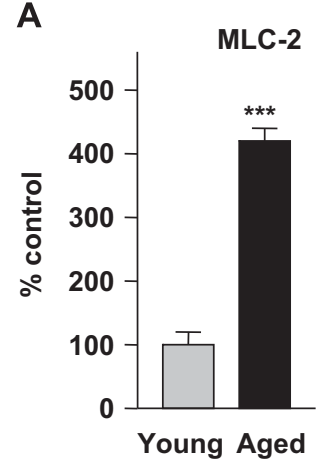

B

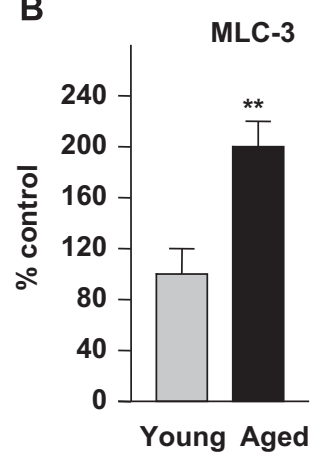

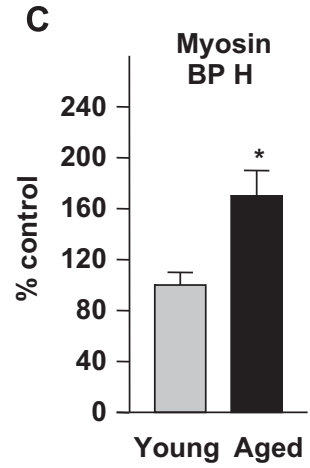

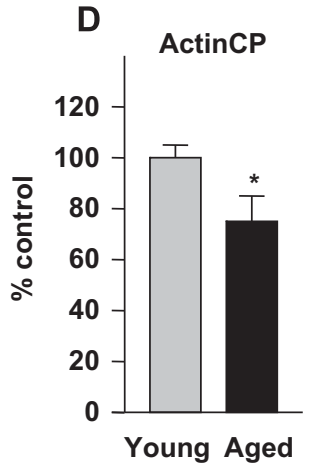

Fig. 3. Graphical presentation of the statistical evaluation of expression changes in MLC-2, MLC-3, myosin-binding protein H actin-capping protein. The comparative proteomic screening of the myofibril-enriched fraction from gastrocnemius preparations was statistically evaluated using an unpaired Student's $t$-test. Data are shown as the mean $\pm \mathrm{SE}(\mathrm{n}=6 ; * p<0.05 ; * * p<0.01$; $* * * p<0.001)$.

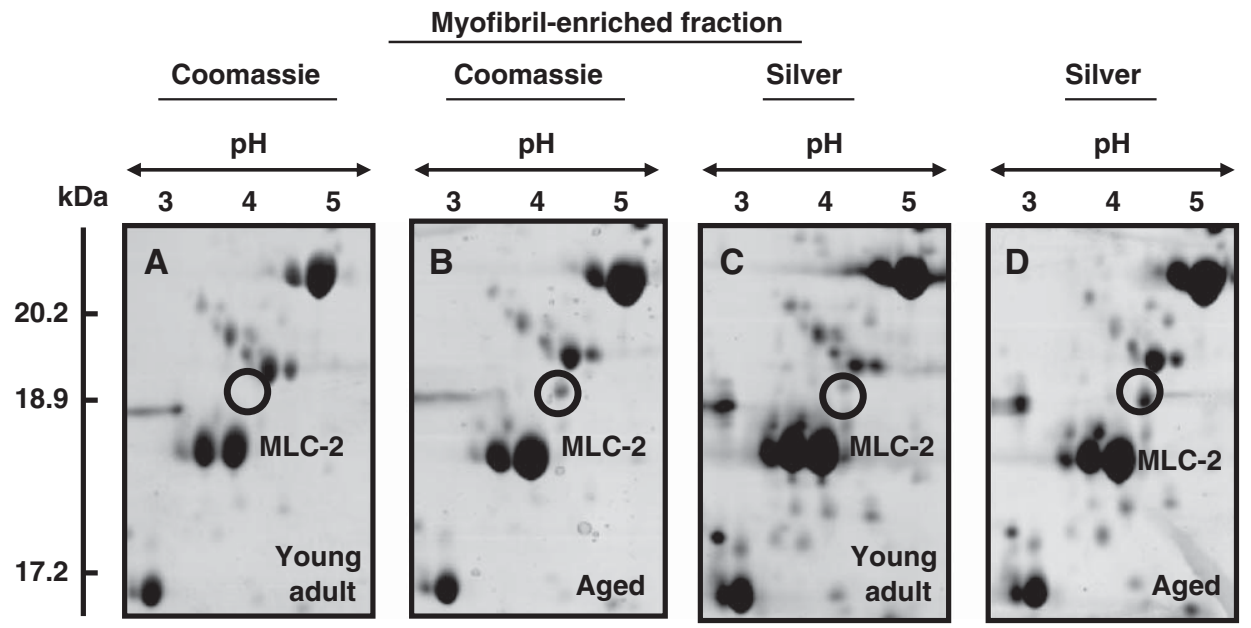

E Mass spectrometric fingerprint of myosin regulatory light chain 2

\begin{tabular}{|c|c|c|c|c|c|}
\hline 1 & MSPKKAKKRL & EGGSSNVFSM & FEQTQIQEFK & EAFTIMDQNR & DGFIDKNDLR \\
\hline 51 & DTFAALGRVN & VKNEEIDEMI & KEAPGPINFT & VFLTMFGEKL & KGADPEETIL \\
\hline 101 & NAFKVFDPEG & KGSLKADYVR & EMLTTQAERF & SKEEIDQMFA & AFPPDVTGNL \\
\hline 151 & DYKNLVHIIT & HGEEKD & & & \\
\hline
\end{tabular}

Ventricular/cardiac muscle isoform-Rattus norvegicus-gil127167I

Fig. 4. Proteomic analysis of MLC-2 in aged myofibrils. Circles mark protein spots that correspond to MLC-2. The mass spectrometric identification of the 2-D spot revealed an approximate $95 \%$ coverage of the amino acid sequence of MLC-2.

was determined (Figs. 6 and 7) in order to confirm the suitability of this new candidate protein for establishing a more complete biomarker signature of sarcopenia of old age.

\section{2-D gel electrophoretic analysis of total extracts from aged muscle}

Prior to the gel electrophoretic analysis of the myofibril-enriched fraction from aged muscle, crude tissue extracts were investigated. In general, any subcellular fractionation step performed during the preparation of protein extracts may introduce artifacts, such as protein clustering, absorption, desorption, entrapment and/or degradation. It is therefore essential to evaluate results from subproteomic studies, as described below with the myofibril-enriched fraction, by also analysing crude total tissue extracts. Fig. 1 summarises the initial screening of the aged muscle proteome using gel systems that cover the $\mathrm{pH}$ range from 4 to 11. Analytical gels were stained with Coomassie Blue (Fig. 1A-E) or silver (Fig. 1F-J), and densitometric scanning revealed altered expression levels for 10 contractile proteins, as listed in Table 1. Mass spectrometry identified these muscle proteins as distinct 

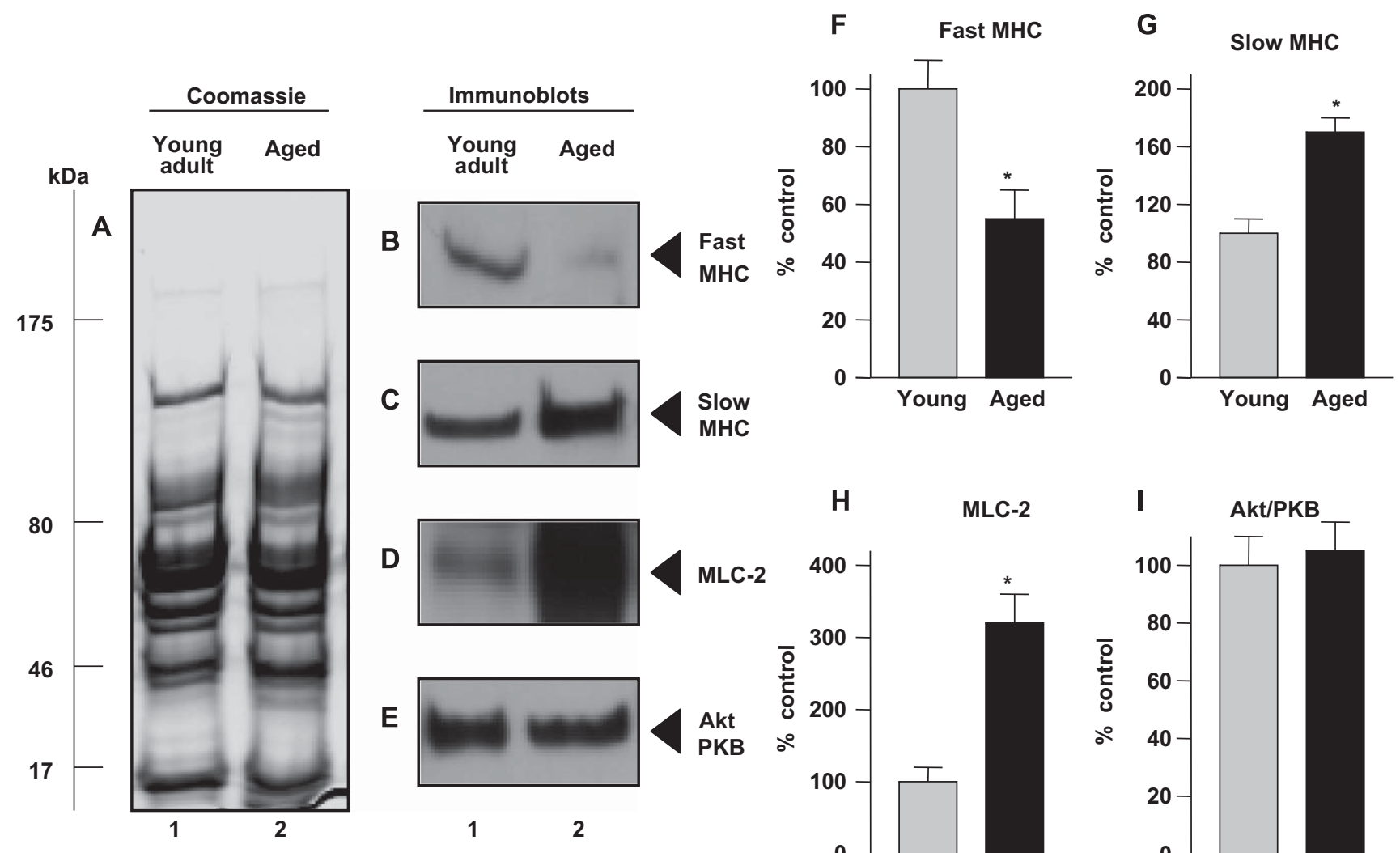

Fig. 5. Immunoblot analysis of fast MHC, slow MHC, MLC-2 and Akt/PKB, respectively, in aged myofibrils. (F-I) Graphical presentation of the statistical evaluation of expression changes. Expression levels were compared using an unpaired Student's $t$-test. Data are shown as the mean $\pm \mathrm{SE}\left(\mathrm{n}=6 ;{ }^{*} p<0.05\right)$.

isoforms of MLC, as well as myosin-binding protein $\mathrm{H}$, tropomyosin, actin and troponin. The abundance of fast and slow MLCs was clearly decreased and increased, respectively, during aging. Two landmark proteins and their established age-related changes in expression were chosen to standardize the narrow $\mathrm{pH}$-range gel system used in this study. Landmark protein LM1 represented the glycolytic enzyme enolase (Fig. 1E) and landmark protein LM2 corresponded to the mitochondrial enzyme ATP synthase (Fig. 1J). The decrease in the glycolytic marker and concomitant increase in the mitochondrial protein agrees with the findings of previous proteomic analyses (Doran et al., 2009).

\section{2-D gel electrophoretic analysis of the myofibril- enriched fraction from aged muscle}

Myofibrils were isolated from rat skeletal muscle homogenates by an established method (Zhukarev et al., 1997; Bassaglia et al., 2005). Fig. 2A, B illustrates the predominant structures found in the myofibril-enriched fraction. Besides bright-field microscopy, also dye staining and immuno-decoration was carried out to evaluate the quality of the subcellular fractionation protocol. Both, methylene blue and immunofluorescence staining of isolated myofibrils with an antibody to actin revealed a regular striation pattern in the longitudinal direction of isolated myofibrillar structures (not shown), indicating a successful enrichment of the contractile machinery by this method (Zhukarev et al., 1997). Two protein dye methods were used to determine the expression pattern of the soluble myofibrillar proteome. Fig. $2 \mathrm{C}-\mathrm{F}$ shows the protein population of the young adult versus aged gastrocnemius muscle stained with Coomassie Blue or silver, respectively. Both dyes indicated an overall comparable protein pattern of the differently aged proteomes in two-dimensional gels. In order to detect subtle changes in the abundance of individual protein species and/or potential switches in distinct isoforms, labelled slab gels were analysed by densitometric scanning. Images were compared with the Progenesis SameSpots analysis programme, which is an advanced software tool for the evaluation of highresolution two-dimensional gels and the generation of reliable proteomic data.

\section{Proteomic profiling of MLCs in aged myofibrils}

Two-dimensional protein spots with a significant change in density were identified by mass spectrometry 
Table 2. Proteomic profiling of myosin light chains in aged skeletal muscle.

\begin{tabular}{|c|c|c|c|c|c|c|c|c|}
\hline $\begin{array}{l}\text { Accession } \\
\text { number }\end{array}$ & $\begin{array}{l}\text { Name of identified } \\
\text { muscle protein }\end{array}$ & $\begin{array}{l}\text { Peptides } \\
\text { matched }\end{array}$ & Peptide sequence & $\begin{array}{l}\text { Sequence } \\
\text { coverage } \\
(\%)\end{array}$ & $\begin{array}{l}\text { Molecular } \\
\text { mass (kDa) }\end{array}$ & $\begin{array}{l}\text { Isoleletric } \\
\text { point }(\mathrm{pI})\end{array}$ & $\begin{array}{l}\text { Mascot } \\
\text { score }\end{array}$ & $\begin{array}{l}\text { Fold } \\
\text { change }\end{array}$ \\
\hline gi $|127167|$ & Myosin light chain MLC-2 & 16 & $\begin{array}{l}\text { KVFDPEGKG } \\
\text { RDTFAALGRV } \\
\text { KGSLKADYVRE } \\
\text { REMLTTQAERF } \\
\text { KNEEIDEMIKE } \\
\text { RDGFIDKNDLRD } \\
\text { KEAFTIMDQNRD } \\
\text { KGADPEETILNAFKV } \\
\text { KNLVHIITHGEEKD } \\
\text { RVNVKNEEIDEMIKE } \\
\text { KLKGADPEETILNAFKV } \\
\text { KADYVREMLTTQAERF } \\
\text { KEAPGPINFTVFLTMFGEKL } \\
\text { RLEGGSSNVFSMFEQTQIQEFKE } \\
\text { KRLEGGSSNVFSMFEQTQIQEFKE } \\
\text { RFSKEEIDQMFAAFPPDVTGNLDYKN }\end{array}$ & 95 & 18.88 & 4.86 & $1.01 \mathrm{e}+03$ & +4.10 \\
\hline gi $|6981240|$ & Myosin light chain MLC-3 & 2 & $\begin{array}{l}\text { KIKIEFTPEQIEEFKE } \\
\text { RLTEDEVEKLMAGQEDSNGCINYEAFVKH }\end{array}$ & 35 & 22.16 & 5.03 & $1.48 \mathrm{e}+02$ & +2.00 \\
\hline gi $|149058581|$ & Myosin binding protein $\mathrm{H}$ & 5 & $\begin{array}{l}\text { KLGLQGYVLELCRE } \\
\text { KAAIDILVIEKPGPPSSIKL } \\
\text { RYHPTTCTVSDLIIGNSYSFRV } \\
\text { REFTERDFSEAPSFTQPLADRT } \\
\text { KLLDVWGCNAALEWMPPQDTGNTELLGYTVQKA }\end{array}$ & 20 & 52.63 & 6.0 & $2.29 \mathrm{e}+02$ & +1.70 \\
\hline gi $|6981240|$ & Myosin light chain MLC-3 & 4 & $\begin{array}{l}\text { KDTGTYEDFVEGLRV } \\
\text { KIEFTPEQIEEFKE } \\
\text { RVFDKEGNGTVMGAELRH } \\
\text { KNKDTGTYEDFVEGLRV }\end{array}$ & 48 & 22.16 & 5.03 & $4.66 \mathrm{e}+02$ & +1.60 \\
\hline gi $|149024411|$ & Actin capping protein & 9 & $\begin{array}{l}\text { KTKNVNGLRS } \\
\text { RSTLNTIYFGKT } \\
\text { KDYLLCDYNRD } \\
\text { RLVEDMENKIRS } \\
\text { KSGSGTMNLGGSLTRQ } \\
\text { KLTSTVMLWLQTNKS } \\
\text { KLEVEANNAFDQYRD } \\
\text { RKLEVEANNAFDQYRD } \\
\text { RSPWSNKYDPPLEDGAMPSARL }\end{array}$ & 37 & 28.20 & 6.33 & $5.54 \mathrm{e}+02$ & -1.50 \\
\hline
\end{tabular}




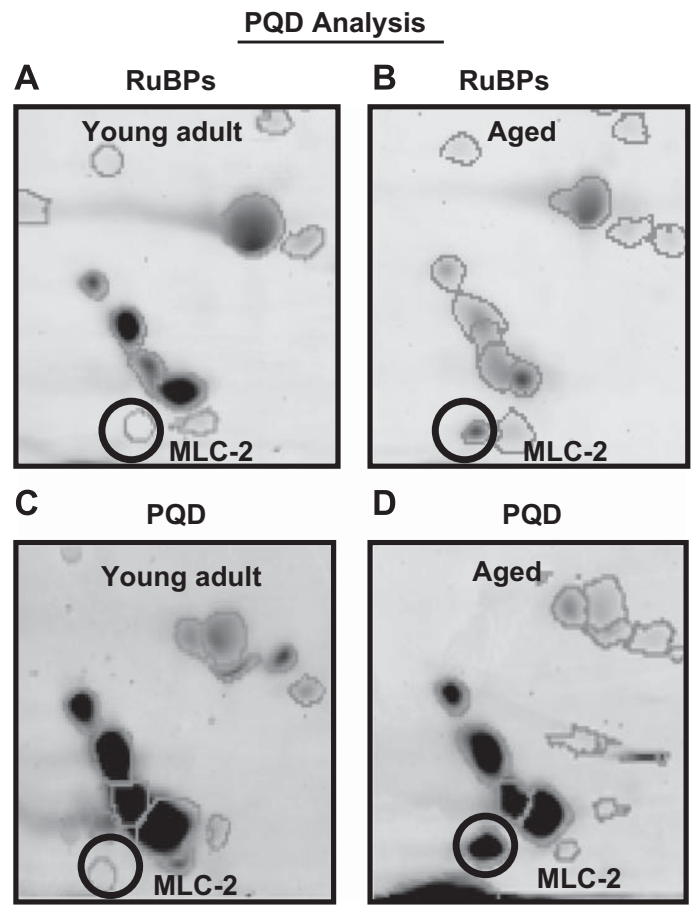

Fig. 6. Phosphoproteomic analysis of MLC-2 in aged muscle. The phosphorylation status of MLC-2 is illustrated by comparative total protein (A, B) and specific phosphoprotein (C, D) staining. Gels were labelled with the fluorescent phosphoprotein gel stain Pro-Q Diamond (PQD) and the fluorescent protein dye ruthenium II bathophenanthroline disulfonate chelate (RuBPs).

using an Ion Trap LC/MS or an LTQ-Orbitrap hybrid apparatus. Trypsin fragments of candidate proteins were generated from isolated gel plugs and then individual peptide sequences determined by fragmentation analysis. As listed in Table 2, muscle aging appears to affect especially the expression of the MLC class of myofibrillar proteins, as assessed by proteomic screening of the soluble myofibrillar fraction. Fig. 3A-D shows the graphical presentation of expression changes in MLC-2, MLC-3, myosin-binding protein $\mathrm{H}$ and actin-capping protein. Table 2 lists the identified proteins and their corresponding unique accession numbers, the number of matched peptides, the sequence of individual peptides, sequence coverage, molecular mass, isoelectric point, Mascot score and fold change. It is important to stress that gel electrophoresis-based methods usually underestimate the presence of relatively insoluble muscle proteins. In addition, certain groups of myofibrillar proteins may also not be properly identified by this method and therefore age-induced changes in their density not detected. This might be the case with MHCs, which were not detected in this study. This could be due to less intensive labelling of large and complexed MHC molecules and/or a drastically reduced sensitivity of MHCs to trypsination. However, it was clearly shown by our proteomic approach that a major contractile element, i.e. slow MLC, is increased in senescent preparations. Both, expression of MLC-2 and MLC-3 were enhanced in 26-month-old rat gastrocnemius muscle as compared to 3-month-old fibres.

Since the 4-fold increase in MLC-2 expression represented the highest level of change in the contractile protein complement, we have focused our study on this slow isoform. Fig. 4A-D shows expanded views of the large two-dimensional gels displayed in Fig. 2C-F, focusing on $\mathrm{pH}$ range 3-5 and molecular mass region 15-25 kDa. The Coomassie- or silver-stained gels with young adult versus aged gastrocnemius muscle clearly demonstrated increased levels of a two-dimensional spot of approximately $19 \mathrm{kDa}$. The mass spectrometric analysis identified this contractile protein as the ventricular/cardiac muscle isoform MLC-2 (gi|127167|) with a pI value of 4.86 and an apparent molecular mass $18.88 \mathrm{kDa}$. The sequence of the MLC-2 isoform was matched by 16 different peptides resulting in 95\% sequence coverage (Table 2; Fig. 4E). For comparison, actin-capping protein was slightly reduced and myosinbinding protein $\mathrm{H}$ slightly increased during fibre aging. One-dimensional immunoblotting confirmed increased MLC-2 expression in senescent muscle and indicated a general fast-to-slow transformation process during aging. The Coomassie-stained gel in Fig. 5A shows a relatively comparable protein band pattern in young adult and aged fibres. The expression of the abundant kinase Akt/PKB was found not to be affected by muscle aging and could therefore be employed as a convenient standard for equal loading between individual gel lanes (Fig. 5E, I). Differential immuno-decoration with antibodies to the fast versus the slow class of MHCs confirmed a gradual shift to slower twitch characteristics in aged gastrocnemius muscle (Fig. 5B, C, F, G). Since monoclonal antibody MY-32 does not discriminate between the different fast MHC isoforms IIA, IIB and IID, results have to be interpreted with caution. The immunoblot analysis shows a general trend of reduced fast MHC expression in aged muscle. However, one cannot deduce the biochemical fate of individual subspecies of this contractile element from this analysis. Importantly, immunoblotting confirmed the drastic increase in the expression of MLC-2 (Fig. 5D, H). The age-dependent adaptation of senescent myofibrils appears to be associated with a drastic remodeling of the contractile apparatus.

\section{Increased abundance and phosphorylation of MLC-2 in aged gastrocnemius muscle}

Fig. 6 displays expanded views of analytical twodimensional gels with a focus on $\mathrm{pH}$ range 4-5 and molecular mass region $15-20 \mathrm{kDa}$. The protein complements studied represent total tissue extracts of the 

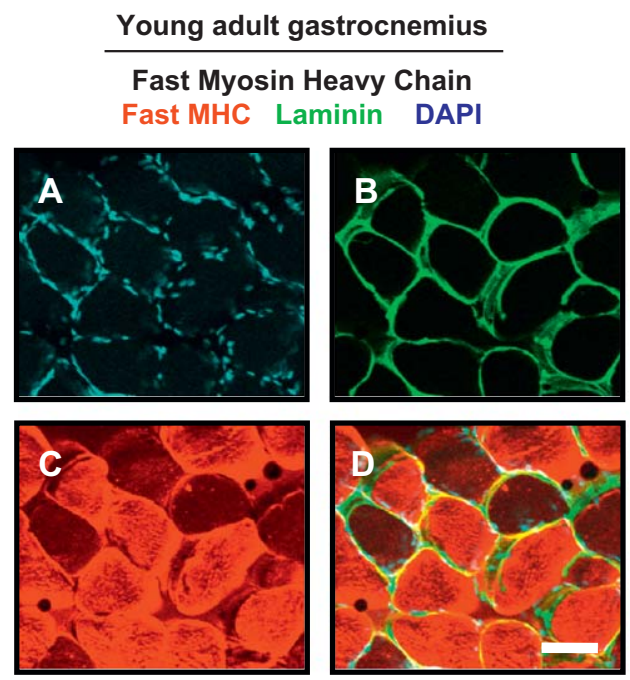

Young adult gastrocnemius

Slow Myosin Light Chain

Slow MLC2 Laminin DAPI
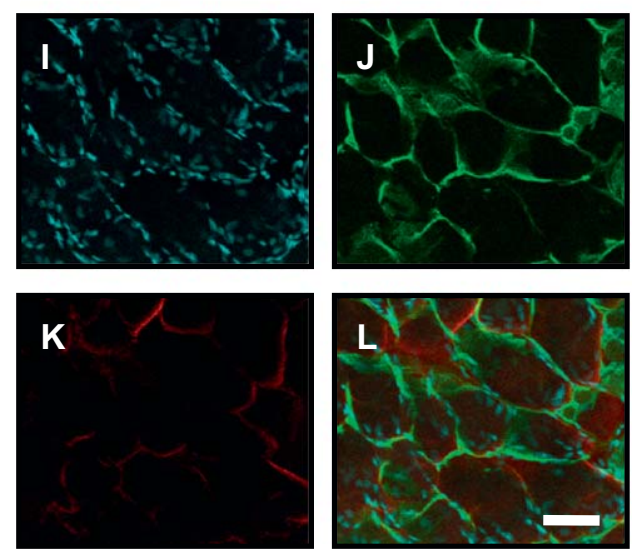

\section{Senescent gastrocnemius \\ Fast Myosin Heavy Chain \\ Fast MHC Laminin DAPI}
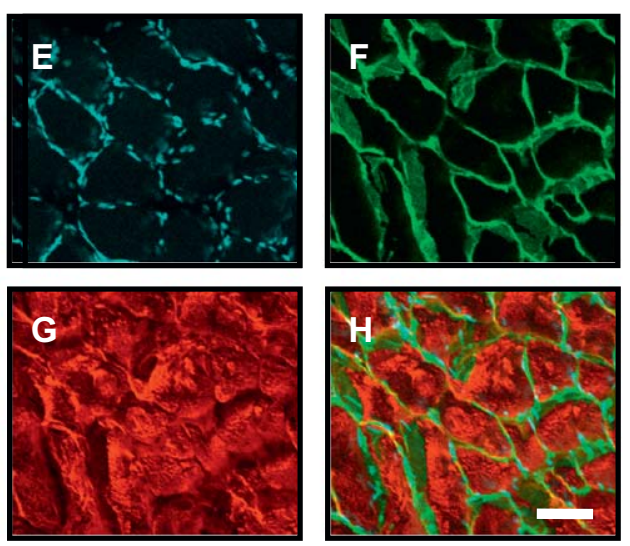

Senescent gastrocnemius

Slow Myosin Light Chain

Slow MLC2 Laminin DAPI
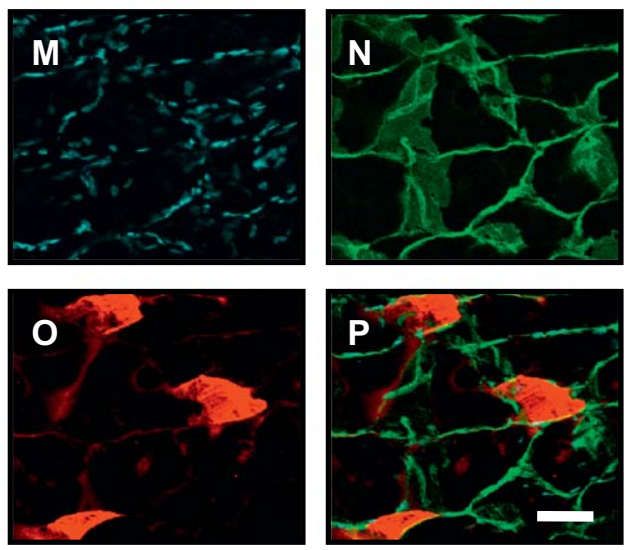

Fig. 7. Immunofluorescence localization of MLC-2 and fast MHC in aged skeletal muscle. Surface membranes were stained with anti-laminin antibodies and nuclei were labelled with DAPI. Bars: $40 \mu \mathrm{m}$.

soluble proteome from whole skeletal muscle preparations. In agreement with the results shown in Fig. 4, the slow MLC-2 spot is increased in its abundance in aged muscle as compared to young adult fibres. Interestingly, a comparative analysis with the fluorescent protein dye RuBPs and the phosphoprotein-specific dye ProQ Diamond revealed that the phosphorylation level of the slow MLC-2 isoform is drastically elevated in senescent gastrocnemius muscle (Fig. 6A-D). As previously reported by our laboratory, this specific protein spot exhibits the highest change in phosphorylation during skeletal muscle aging (Gannon et al., 2008). While the increase in protein expression was found to be approximately 9-fold, the degree of phosphorylation of MLC-2 was determined to be over 28 -fold. This suggests a 3 -fold increase in phosphorylation of site chains in this slow protein isoform during fibre aging.

Since biochemical studies with crude tissue extracts or subcellular fractions from muscle homogenates do not differentiate between different fibre types within a given muscle, ideally immunofluorescence microscopy should be carried out to confirm and complement proteomic findings. We have therefore performed a confocal microscopy survey with a fast and a slow marker of the contractile apparatus in young adult versus aged skeletal muscle. The fibre periphery was marked with the extracellular matrix component laminin and nuclei were labelled with DAPI (Fig. 7). Immuno-decoration with an antibody to fast MHCs revealed a drastic decrease in abundance of these contractile proteins in the aged fibre population (Fig. 7A-H). In stark contrast, the aged gastrocnemius muscle showed a dramatic increase of individually labelled fibres with a high content of MLC2 (Fig. 7I-P). Images with the combined labelling of laminin, nuclei and contractile elements are presented in Figs. 7D, H, L and P. Confocal microscopy demonstrated that the increased levels of MLC-2 are restricted to individual aged fibres and that the decreased density 
of fast MHCs appears to affect most aged fibres in a similar way.

\section{Discussion}

Natural aging is a fundamental biological process and influenced by both genetic and environmental factors. As recently reviewed by Vijg and Campisi (2008), sarcopenia-related muscle weakness represents a conserved aging phenotype and affects a diverse range of species, including Caenorhabditis elegans, Drosophila melanogaster, Mus musculus, Rattus rattus and Homo sapiens. Since cross-sectional studies with differently aged human muscle specimens have to be often interpreted with caution due to fundamental differences in general lifestyle, activity patterns and food habits of examined individuals (Proctor et al., 1999; Melton et al., 2000; Lindle et al., 1997), initial model studies with inbred animal strains can give crucial data for the design of more advanced studies in human populations (Doran et al., 2007b). Therefore, the alternative analysis of aged animals with a suitable phenotype plays a vital role in modern biogerontology. One of the most widely employed biomedical model system of sarcopenia is the senescent Wistar rat (Doran et al., 2009). The comparative proteomic profiling of 7 -month- versus 18 -monthversus 30-month-old rats has shown that 7-month- and 18-month-old muscle exhibit a surprisingly similar protein expression pattern (Piec et al., 2005). We have therefore used young adult (3-months) versus senescent (26-months) skeletal muscle fibres to determine marked differences in the aging skeletal muscle proteome. Using a combination of two-dimensional gel electrophoresis, mass spectrometry, immunoblotting and confocal microscopy, this study has clearly revealed that the expression of the slow MLC-2 isoform of myosin light chain is drastically increased in aged skeletal muscle. This finding supports the idea that muscle aging is associated with a transformation to a more aerobicoxidative metabolism in a slower twitching fibre population (Edstrom et al., 2007).

In addition to the fact that the skeletal muscle belly usually contains higher levels of connective and fatty tissue in elderly patients, both of the main types of muscle fibres are lost in aged muscles. However, large-scale histochemical studies agree that a noticeably higher loss in type II fibres occurs as compared to slower twitching type I fibres (Vandervoort, 2002). The proteomic identification of MLC-2 as being a contractile element with an increased abundance in aged muscle fibres is in agreement with a previous histochemical study by Klitgaard et al. (1990). This makes the slow-type MLC-2 protein species a potentially useful indicator of the fast-to-slow transformation process in senescent muscles. In analogy to the proteomic findings on MLCs presented here, a recent gel electrophoretic analysis of aging rat sciatic nerve and gastrocnemius muscle by Capitanio et al. (2009) has revealed a distinct age-dependent transformation process within the pool of $\mathrm{MHC}$ isoforms. Silver staining of $\mathrm{MHC}$ bands revealed a transition from fast MHC-IIb to MHC-IIa to slow MHC-I in 8-month- versus 22-month-old muscles. This altered pattern of MHC expression agrees in general with the molecular processes that occur during fast-to-slow transitions, such as adaptations following chronic low-frequency stimulation of fast muscles (Pette and Staron, 2001) or endurance exercise (Sullivan et al., 1995).

As reviewed by Andersen (2003), muscle fibre type adaptation in the elderly includes extended grouping of fibre types, as well as morphological alterations in the size and appearance of individual fibres. Since cycles of denervation and reinnervation are associated with muscle aging, a complex adaptation of motor units occurs in sarcopenia (Larsson, 1998). The immunofluorescence labelling of slow MLC-2 in a select group of fibres supports the hypothesis that sarcopenia triggers an extensive rearrangement of innervation patterns. A slower-twitching fibre population with increased levels of mitochondrial fatty acid oxidation would clearly require an altered degree of fuel supply. That a metabolic switch takes place in senescent muscles is supported by the finding that the fatty acid-binding protein FABP and the oxygen carrier myoglobin are increased during aging (Doran et al., 2008). Both proteins have previously been established as limiting factors of aerobic-oxidative metabolism in slow-twitching fibres (Kaufmann et al., 1989). Thus, both changes in contractile kinetics and metabolic adaptations suggest an age-related switch to a slower muscle type.

As previously reported, the contractile elements actin, tropomyosin and MLC undergo a drastic increase in phosphorylation during aging (Gannon et al., 2008). Here, we could show that the slow MLC-2 isoform represents an excellent marker of fibre type switching and that its degree of phosphorylation is increased in aged muscle. The proteomic analysis of the age-related transformation of fibres agrees with findings from artificially induced fibre type transitions due to chronic low-frequency stimulation. Fast-to-slow transformation is associated with major alterations in the density and isoform expression pattern of both MHCs (Kirschbaum et al., 1989) and MLCs (Gonzalez et al., 2002). Changes in the expression levels and post-translational modifications of key contractile elements is a clear indication that senescent motor units undergo major physiological adaptations. One of the pathophysiological consequences of this change is an impaired ability of aged muscles to adapt to repetitive mechanical loading (Cutlip et al., 2007), resulting in a reduced speed of contraction. 
This proteomic and cell biological study into the fate of myofibrillar components during muscle aging has shown the usefulness of molecular approaches in developing the basis of evidence for improving public health strategies to promote healthy aging. In the longterm, the systematic cataloguing of aging-related muscle proteins, such as the slow MLC-2 isoform, may lead to the establishment of a disease-specific biomarker signature of sarcopenia. Reliable proteomic data might then be used to design novel diagnostic methods and improve therapeutic approaches for the prevention of contractile impairments in the rapidly aging human population.

\section{Acknowledgements}

Research was supported by a principal investigator grant from Science Foundation Ireland (SFI-04/IN3/ B614) and equipment grants from the Irish Health Research Board and the Higher Education Authority (HRB-EQ/2003/3, HEA-RERGS-07-NUIM, HRB-EQ/ 2004/2). The authors thank Dr. Marina Lynch (Trinity College Dublin) for her generous help obtaining aged rat muscle, Ms. Caroline Batchlor (NUI Maynooth) for assistance with mass spectrometry and Dr. Ica Dix (NUI Maynooth) for help with confocal microscopy.

\section{References}

Alnaqeeb, M.A., Goldspink, G., 1987. Changes in fibre type, number and diameter in developing and ageing skeletal muscle. J. Anat. 153, 31-45.

Andersen, J.L., 2003. Muscle fibre type adaptation in the elderly human muscle. Scand. J. Med. Sci. Sports 13, 40-47.

Balagopal, P., Rooyackers, O.E., Adey, D.B., Ades, P.A., Nair, K.S., 1997. Effects of aging on in vivo synthesis of skeletal muscle myosin heavy-chain and sarcoplasmic protein in humans. Am. J. Physiol. 273, E790-E800.

Bassaglia, Y., Cebrian, J., Covan, S., Garcia, M., Foucrier, J., 2005. Proteasomes are tightly associated to myofibrils in mature skeletal muscle. Exp. Cell Res. 302, 221-232.

Bozzo, C., Spolaore, B., Toniolo, L., Stevens, L., Bastide, B., Cieniewski-Bernard, C., Fontana, A., Mounier, Y., Reggiani, C., 2005. Nerve influence on myosin light chain phosphorylation in slow and fast skeletal muscles. FEBS J. 272, 5771-5785.

Capitanio, D., Vasso, M., Fania, C., Moriggi, M., Vigano, A., Procacci, P., Magnaghi, V., Gelfi, C., 2009. Comparative proteomic profile of rat sciatic nerve and gastrocnemius muscle tissues in ageing by 2-D DIGE. Proteomics 9, 2004-2020.

Carlson, B.M., 2004. Denervation and the aging of skeletal muscle. Bas. Appl. Myol. 14, 135-140.

Chabi, B., Ljubicic, V., Menzies, K.J., Huang, J.H., Saleem, A., Hood, D.A., 2008. Mitochondrial function and apoptotic susceptibility in aging skeletal muscle. Aging Cell 7, 2-12.
Chevallet, M., Luche, S., Rabilloud, T., 2006. Silver staining of proteins in polyacrylamide gels. Nat. Protoc. 1, 1852-1858.

Clark, K.A., McElhinny, A.S., Beckerle, M.C., Gregorio, C.C., 2002. Striated muscle cytoarchitecture: an intricate web of form and function. Annu. Rev. Cell Dev. Biol. 18, 637-706.

Cutlip, R.G., Baker, B.A., Geronilla, K.B., Kashon, M.L., $\mathrm{Wu}$, J.Z., 2007. The influence of velocity of stretch and dash shortening contractions on muscle performance during chronic exposure: age effects. Appl. Physiol. Nutr. Metab. 32, 443-453.

Degens, H., 1998. Age-related changes in the microcirculation of skeletal muscle. Adv. Exp. Med. Biol. 454, 343-348.

Delbono, O., O'Rourke, K.S., Ettinger, W.H., 1995. Excitation-calcium release uncoupling in aged single human skeletal muscle fibers. J. Membr. Biol. 148, 211-222.

Doherty, T.J., 2003. Aging and sarcopenia. J. Appl. Physiol. 95, 1717-1727.

Donoghue, P., Doran, P., Dowling, P., Ohlendieck, K., 2005. Differential expression of the fast skeletal muscle proteome following chronic low-frequency stimulation. Biochim. Biophys. Acta 1752, 166-176.

Donoghue, P., Doran, P., Wynne, K., Pedersen, K., Dunn, M.J., Ohlendieck, K., 2007. Proteomic profiling of chronic low-frequency stimulated fast muscle. Proteomics 7, 3417-3430.

Doran, P., Dowling, P., Lohan, J., McDonnell, K., Poetsch, S., Ohlendieck, K., 2004. Subproteomics analysis of $\mathrm{Ca}^{2+}$. binding proteins demonstrates decreased calsequestrin expression in dystrophic mouse skeletal muscle. Eur. J. Biochem. 271, 3943-3952.

Doran, P., Gannon, J., O’Connell, K., Ohlendieck, K., 2007 a. Aging skeletal muscle shows a drastic increase in the small heat shock proteins alphaB-crystallin/HspB5 and cvHsp/ HspB7. Eur. J. Cell Biol. 86, 629-640.

Doran, P., Gannon, J., O’Connell, K., Ohlendieck, K., 2007 b. Proteomic profiling of animal models mimicking skeletal muscle disorders. Proteomics Clin. Appl. 1, 1169-1184.

Doran, P., O'Connell, K., Gannon, J., Kavanagh, M., Ohlendieck, K., 2008. Opposite pathobiochemical fate of pyruvate kinase and adenylate kinase in aged rat skeletal muscle as revealed by proteomic DIGE analysis. Proteomics 8, 364-377.

Doran, P., Donoghue, P., O’Connell, K., Gannon, J., Ohlendieck, K., 2009. Proteomics of skeletal muscle aging. Proteomics 9, 989-1003.

Edstrom, E., Altun, M., Bergman, E., Johnson, H., Kullberg, S., Ramirez-Leon, V., Ulfhake, B., 2007. Factors contributing to neuromuscular impairment and sarcopenia during aging. Physiol. Behav. 92, 129-135.

Edstrom, L., Larsson, L., 1987. Effects of age on contractile and enzyme-histochemical properties of fast- and slowtwitch single motor units in the rat. J. Physiol. 392, 129-145.

Faulkner, J.A., Larkin, L.M., Claflin, D.R., Brooks, S.V., 2007. Age-related changes in the structure and function of skeletal muscles. Clin. Exp. Pharmacol. Physiol. 34, 1091-1096.

Fitts, R.H., 2008. The cross-bridge cycle and skeletal muscle fatigue. J. Appl. Physiol. 104, 551-558. 
Gannon, J., Staunton, L., O'Connell, K., Doran, P., Ohlendieck, K., 2008. Phosphoproteomic analysis of aged skeletal muscle. Int. J. Mol. Med. 22, 33-42.

Gelfi, C., Vigano, A., Ripamonti, M., Pontoglio, A., Begum, S., Pellegrino, M.A., Grassi, B., Bottinelli, R., Wait, R., Cerretelli, P., 2006. The human muscle proteome in aging. J. Proteome Res. 5, 1344-1353.

Gonzalez, B., Negredo, P., Hernando, R., Manso, R., 2002. Protein variants of skeletal muscle regulatory myosin light chain isoforms: prevalence in mammals, generation and transitions during muscle remodeling. Pflugers Arch. 443, 377-386.

Gordon, A.M., Homsher, E., Regnier, M., 2000. Regulation of contraction in striated muscle. Physiol. Rev. 80, 853-924.

Kanski, J., Hong, S.J., Schoneich, C., 2005. Proteomic analysis of protein nitration in aging skeletal muscle and identification of nitrotyrosine-containing sequences in vivo by nanoelectrospray ionization tandem mass spectrometry. J. Biol. Chem. 280, 24261-24266.

Kaufmann, M., Simoneau, J.A., Veerkamp, J.H., Pette, D., 1989. Electrostimulation-induced increases in fatty acidbinding protein and myoglobin in rat fast-twitch muscle and comparison with tissue levels in heart. FEBS Lett. 245, 181-184.

Kayani, A.C., Morton, J.P., McArdle, A., 2008. The exerciseinduced stress response in skeletal muscle: failure during aging. Appl. Physiol. Nutr. Metab. 33, 1033-1041.

Kirschbaum, B.J., Heilig, A., Hartner, K.T., Pette, D., 1989. Electrostimulation-induced fast-to-slow transitions of myosin light and heavy chains in rabbit fast-twitch muscle at the mRNA level. FEBS Lett. 243, 123-126.

Klitgaard, H., Mantoni, M., Schiaffino, S., Ausoni, S., Gorza, L., Laurent-Winter, C., Schnohr, P., Saltin, B., 1990. Function, morphology and protein expression of ageing skeletal muscle: a cross-sectional study of elderly men with different training backgrounds. Acta Physiol. Scand. 140, 41-54.

Koh, T.J., 2002. Do small heat shock proteins protect skeletal muscle from injury? Exerc. Sport Sci. Rev. 30, 117-121.

Kreutziger, K.L., Gillis, T.E., Davis, J.P., Tikunova, S.B., Regnier, M., 2007. Influence of enhanced troponin $\mathrm{C} \mathrm{Ca}^{2+}$ binding affinity on cooperative thin filament activation in rabbit skeletal muscle. J. Physiol. 583, 337-350.

Kumar, C.C., Cribbs, L., Delaney, P., Chien, K.R., Siddiqui, M.A., 1986. Heart myosin light chain 2 gene. Nucleotide sequence of full length cDNA and expression in normal and hypertensive rat. J. Biol. Chem. 261, 2866-2872.

Larsson, L., 1998. The age-related motor disability: underlying mechanisms in skeletal muscle at the motor unit, cellular and molecular level. Acta Physiol. Scand. 163, S27-S29.

Larsson, L., Edstrom, L., 1986. Effects of age on enzymehistochemical fibre spectra and contractile properties of fast- and slow-twitch skeletal muscles in the rat. J. Neurol. Sci. 76, 69-89.

Larsson, L., Ansved, T., Edstrom, L., Gorza, L., Schiaffino, S., 1991. Effects of age on physiological, immunohistochemical and biochemical properties of fast-twitch single motor units in the rat. J. Physiol. 443, 257-275.

Lee, C.E., McArdle, A., Griffiths, R.D., 2007. The role of hormones, cytokines and heat shock proteins during agerelated muscle loss. Clin. Nutr. 26, 524-534.
Lindle, R.S., Metter, E.J., Lynch, N.A., Fleg, J.L., Fozard, J.L., Tobin, J., Roy, T.A., Hurley, B.F., 1997. Age and gender comparisons of muscle strength in 654 women and men aged 20-93 yr. J. Appl. Physiol. 83, 1581-1587.

Lombardi, A., Silvestri, E., Cioffi, F., Senese, R., Lanni, A., Goglia, F., de Lange, P., Moreno, M., 2009. Defining the transcriptomic and proteomic profiles of rat ageing skeletal muscle by the use of a cDNA array, 2D- and Blue nativePAGE approach. J. Proteom. 72, 708-721.

Lorenzon, P., Bandi, E., de Guarrini, F., Pietrangelo, T., Schafer, R., Zweyer, M., Wernig, A., Ruzzier, F., 2004. Ageing affects the differentiation potential of human myoblasts. Exp. Gerontol. 39, 1545-1554.

Marzetti, E., Leeuwenburgh, C., 2006. Skeletal muscle apoptosis, sarcopenia and frailty at old age. Exp. Gerontol. 41, 1234-1238.

Melton, L.J., Khosla, S., Crowson, C.S., O'Connor, M.K., O'Fallon, W.M., Riggs, B.L., 2000. Epidemiology of sarcopenia. J. Am. Geriatr. Soc. 48, 625-630.

Morley, J.E., Baumgartner, R.N., Roubenoff, R., Mayer, J., Nair, K.S., 2001. Sarcopenia. J. Lab. Clin. Med. 137, 231-243.

Neuhoff, V., Arold, N., Taube, D., Ehrhardt, W., 1988. Improved staining of proteins in polyacrylamide gels including isoelectric focusing gels with clear background at nanogram sensitivity using Coomassie Brilliant Blue G250 and R-250. Electrophoresis 9, 255-262.

Nolan, Y., Maher, F.O., Martin, D.S., Clarke, R.M., Brady, M.T., Bolton, A.E., Mills, K.H., Lynch, M.A., 2005. Role of interleukin-4 in regulation of age-related inflammatory changes in the hippocampus. J. Biol. Chem. 280, 9354-9362.

O’Connell, K., Gannon, J., Doran, P., Ohlendieck, K., 2007. Proteomic profiling reveals a severely perturbed protein expression pattern in aged skeletal muscle. Int. J. Mol. Med. 20, 145-153.

O’Connell, K., Gannon, J., Doran, P., Ohlendieck, K., 2008a. Reduced expression of sarcalumenin and related $\mathrm{Ca}^{2+}$. regulatory proteins in aged rat skeletal muscle. Exp. Gerontol. 43, 958-961.

O’Connell, K., Doran, P., Gannon, J., Ohlendieck, K., 2008 b. Lectin-based proteomic profiling of aged skeletal muscle: decreased pyruvate kinase isozyme M1 exhibits drastically increased levels of N-glycosylation. Eur. J. Cell Biol. 87, 793-805.

Pette, D., Staron, R.S., 1990. Cellular and molecular diversities of mammalian skeletal muscle fibers. Rev. Physiol. Biochem. Pharmacol. 116, 1-76.

Pette, D., Staron, R.S., 2001. Transitions of muscle fiber phenotypic profiles. Histochem. Cell Biol. 115, 359-372.

Piec, I., Listrat, A., Alliot, J., Chambon, C., Taylor, R.G., Bechet, D., 2005. Differential proteome analysis of aging in rat skeletal muscle. FASEB J. 19, 1143-1145.

Prochniewicz, E., Thompson, L.V., Thomas, D.D., 2007. Agerelated decline in actomyosin structure and function. Exp. Gerontol. 42, 931-938.

Proctor, D.N., O’Brien, P.C., Atkinson, E.J., Nair, K.S., 1999. Comparison of techniques to estimate total body skeletal muscle mass in people of different age groups. Am. J. Physiol. 277, E489-E495. 
Rabilloud, T., Strub, J.M., Luche, S., van Dorsselaer, A., Lunardi, J., 2001. A comparison between Sypro Ruby and ruthenium II tris (bathophenanthroline disulfonate) as fluorescent stains for protein detection in gels. Proteomics 1, 699-704.

Rolland, Y., Czerwinski, S., Abellan Van Kan, G., Morley, J.E., Cesari, M., Onder, G., Woo, J., Baumgartner, R., Pillard, F., Boirie, Y., Chumlea, W.M., Vellas, B., 2008. Sarcopenia: its assessment, etiology, pathogenesis, consequences and future perspectives. J. Nutr. Health Aging 12, 433-450.

Squier, T.S., Bigelow, D.J., 2000. Protein oxidation and agedependent alterations in calcium homeostasis. Front. Biosci. 5, 504-526.

Staples, G.O., Bowman, M.J., Costello, C.E., Hitchcock, A.M., Lau, J.M., Leymarie, N., Miller, C., Naimy, H., Shi, X., Zaia, J., 2009. A chip-based amide-HILIC LC/MS platform for glycosaminoglycan glycomics profiling. Proteomics 9, 686-695.

Stasyk, T., Morandell, S., Bakry, R., Feuerstein, I., Huck, C.W., Stecher, G., Bonn, G.K., Huber, L.A., 2005. Quantitative detection of phosphoproteins by combination of two-dimensional difference gel electrophoresis and phosphospecific fluorescent staining. Electrophoresis 26, 2850-2854.
Sullivan, V.K., Powers, S.K., Criswell, D.S., Tumer, N., Larochelle, J.S., Lowenthal, D., 1995. Myosin heavy chain composition in young and old rat skeletal muscle: effects of endurance exercise. J. Appl. Physiol. 78, 2115-2120.

Swartz, D.R., Yang, Z., Sen, A., Tikunova, S.B., Davis, J.P., 2006. Myofibrillar troponin exists in three states and there is signal transduction along skeletal myofibrillar thin filaments. J. Mol. Biol. 361, 420-435.

Thomas, D.R., 2007. Loss of skeletal muscle mass in aging: examining the relationship of starvation, sarcopenia and cachexia. Clin. Nutr. 26, 389-399.

Thompson, L.V., 2009. Age-related muscle dysfunction. Exp. Gerontol. 44, 106-111.

Vandervoort, A.A., 2002. Aging of the human neuromuscular system. Muscle Nerve 25, 17-25.

Vandervoort, A.A., Symons, T.B., 2001. Functional and metabolic consequences of sarcopenia. Can. J. Appl. Physiol. 26, 90-101.

Vijg, J., Campisi, J., 2008. Puzzles, promises and a cure for ageing. Nature 454, 1065-1071.

Zhukarev, V., Sanger, J.M., Sanger, J.W., Goldman, Y.E., Shuman, H., 1997. Distribution and orientation of rhodamine-phalloidin bound to thin filaments in skeletal and cardiac myofibrils. Cell Motil. Cytoskeleton 37, 363-377. 